\title{
"... the thought that I could flip and die today made me feel anxious": A study of the experienced emotions of novice white-water kayakers
}

\author{
Sabrina Krogh Schmidt, ${ }^{1 \star}$ Matt Barker ${ }^{2} \&$ Jennifer Byrne ${ }^{3}$ \\ ${ }^{1}$ University of South-Eastern Norway, Norway; ${ }^{2}$ Auckland University of Technology, \\ New Zealand; ${ }^{3}$ Aston University, United Kingdom
}

\begin{abstract}
Learning to white-water kayak often takes place in a stressful environment. This challenges participants' experiences of the activity, causes emotional responses, and can affect their learning. The purpose of this study is to explore participants' experienced emotions during an educational whitewater kayaking programme. Fifty-eight outdoor students from New Zealand participated. The participants responded to a bespoke questionnaire exploring fleeting somatic arousal and emotion on five different occasions during a kayaking day. Participants' emotions changed during the activity. Excitement was significantly higher than anxiety across the day. Anxiety was highest before starting the activity. No significant difference was found between the male and female participants' emotions. A thematic analysis resulted in five themes describing the participants' emotional experiences. Findings are discussed and related to theory and previous research. These findings present new insights regarding in-the-moment emotional perspectives during a white-water kayaking course for novices.
\end{abstract}

Keywords: white-water kayaking; anxiety; learning; adventure activities; gender perspective

Received: March, 2021; Accepted: November, 2021; Published: January, 2022

\section{Introduction}

White-water kayaking has a long history in the Anglosphere (MacGregor, 1866), starting as an outdoor adventure or recreational activity and developing into competitive sport, an Olympic sport, a tourist attraction, and an educational tool. These activities occur globally where climate and topography align to spawn whitewater rivers and, in the case of artificial white-water parks, even where they do not. New Zealand and North-Western Europe are places where high rainfall and steep

^Correspondence: Sabrina Krogh Schmidt, e-mail: sabrina.k.schmidt@usn.no

(C) 2022 S. K. Schmidt, M. Barker \& J. Byrne. This is an Open Access article distributed under the terms of the Creative Commons Attribution 4.0 International License (https://creativecommons.org/licenses/BY/4.0/), allowing third parties to copy and redistribute the material in any medium or format and to remix, transform, and build upon the material for any purpose, even commercially, provided the original work is properly cited and states its license.

Citation: S. K. Schmidt, M. Barker E F. Byrne. "“... the thought that I could fip and die today made me feel anxious": A study of the experienced emotions of novice white-water kayakers" fournal for Research in Arts and Sports Education, Special issue: Friluftsliv, dannelse, lering og didaktikk, Vol. 6(1), 2022, pp. 51-75. http://dx.doi.org/10.23865/jased.v6.3032 51 
terrain provide the raw materials for this activity. New Zealand has a relatively long history of using white-water activities in both college programmes ( $<18$ yo) e.g. Howick College, St Paul's Collegiate, and tertiary programmes (>18yo) e.g. AUT University, Tai Poutini Polytechnic, Ara Polytechnic. Scandinavia has a shorter history of white-water kayaking but is adopting the pursuit rapidly. Increasingly, visitors arrive in Norway for nature and adventure activities with towns such as Voss capitalising as adventure destinations (Gyimóthy, 2010). White-water activities are seen as valuable to Scandinavian locals (Aas \& Onstad, 2013), where tourists and Norwegian locals are increasingly seeking the thrill of white-water kayaking. Good kayaking rivers are found across the country, and very active white-water recreation communities are found in Sjoa, Voss, Kongsberg-Dagali, Oslo, Arendal, Trondheim, Oppdal, Lillehammer, Sogndal, Valdal, Evje, and Hattfjeldal (Zinke et al., 2018, p. 3). White-water kayaking is now also taught at several educational institutions in Norway, including folk high schools ('folkehøgskoler') and colleges, e.g. Stavern Folk High School, Lyngdal Folk High School, and Voss High School.

Participant and client experiences of emotions in white-water have yet to be fully studied, but this gap needs to be filled to ensure a good experience for both instructors and beginners. This is perhaps more important in Scandinavian countries where the traditional outdoor activities under the 'friluftsliv' model of outdoor education and recreation are more in harmony with nature and less adrenaline-inducing. The Norwegian Canoe Federation recognises that white-water kayaking takes place in a stressful environment, which can evoke negative emotions that prevent learning and a good experience. In the curriculum to become a white-water instructor in Norway, principles of psychological factors are emphasised when instructing beginners and more advanced white-water kayakers (Norwegian Canoe Federation, 2021). A key principle of the federation is that for participants to learn, part of the instructor's role is to prevent high anxiety levels in participants when instructing white-water kayaking (Føllesdal, 1996). The way participants experience emotions related to stress, fear and anxiety when learning white-water kayaking is thus of great importance in the Scandinavian context.

Many outdoor adventure activities emphasise challenges, especially physical challenges, as a central driver of learning (Priest \& Gass, 2018). Experiential learning theory postulates that challenging experiences can be transformed into learning through a person's conscious cycle of experiencing, thinking, acting and reflecting (Kolb, 1984). In the past it has been argued that anxiety plays an important role; that it is the presence of anxiety that impels a learner to tackle the tasks presented (Walsh \& Golins, 1976). However, more recent research shows that anxiety can be so overwhelming that it creates a negative spiral that disrupts motivation and depresses learning (McKenzie, 2003). It has been argued that placing people in stressful situations to help them overcome their fear and therefore grow as individuals (as postulated in the comfort zone model) should not be used to underpin programmes and teaching methodology in outdoor education (Brown, 2008). Indeed, Reed and 
Smith (2021) suggest that participants' debilitating experience of fear can be at odds with the facilitator's expectation of the growth potential of that fearful experience. The best scenario for learning, growth and change is the one where participants feel safe, secure, cared about, experience an optimum level of challenge and are working within their comfort zone (Csikszentmihalyi, 2000; Davis-Berman \& Berman, 2002; Dingle et al., 2006; Hanin, 2000).

Further, positive mood and positive affect, it is suggested, lead to better activation of human memory (Bauml \& Kuhbandner, 2009). This could influence both shortand long-term memories and learning (Moore \& Oaksford, 2002), while anxiety and negative affect have been found to reduce learning and lessen cognitive processing ability (Khan \& Zafar, 2010). Many models explain this relationship, including the information processing model (Humphreys \& Revelle, 1984), selective attention (Braunstein-Bercovitz, 2003), the processing efficiency theory (Eysenck \& Calvo, 1992), and the conscious processing hypothesis (Masters, 1992).

The construct of self-efficacy (Bandura, 1977) has seen continued application to psychology and more recently to outdoor learning domains (Deane et al., 2017). These more recent studies of self-efficacy have seen the original (Bandura, 1977) term 'performance accomplishment' replaced with the term 'mastery experience' (Deane et al., 2017) as the principal mediator of participants' judgements of the strength of their self-efficacy beliefs (Bates \& Khasawnek, 2007; Usher \& Pajares, 2008). Allied to this are the findings of Rose et al. (2010) which conclude that the actual outdoor experiences (mastery experience) account for the most learning on a National Outdoor Leadership Schools course.

Teaching methods that have encouraged 'personal mastery' (Berry \& West, 1993), i.e. a fixed skillset and variable time, have seen renewed interest from outdoor educators (Beames \& Brown, 2016; Gray \& Piggott, 2018), largely due to the wide-reaching benefits of these methodologies (Muntz \& Müller, 2016; Zaichkowsky \& Baltzell, 2001).

Providing positive experiences that develop self-efficacy and perceptions of personal mastery are key to successful outdoor programmes. It therefore seems vital that the facilitator can monitor the students' emotional state and therefore the learning potential of the given experience.

Self-efficacy has an influence on affect, with Laczczynska et al. (2005) finding that general self-efficacy has a positive relationship with positive affect and a negative correlation with negative affect. Factors that both improve performance and self-efficacy are arousal and emotion. These two factors are both antecedents of self-efficacy beliefs (Bandura, 1977; Schunk, 1995) and are related to peak performance in models such as Hardy and Parfitt's (1991) catastrophe model and Hanin and Syrja's (1995) individual zone of optimum function. The extent to which people believe they can exert a controlling influence over a stressful situation has also been shown to vary directly with arousal and performance (Folkman, 1984; Folkman \& Lazarus, 1988), while perceptions of a lack of control have been associated with 
increased anxiety (Endler et al., 2001). Both perceived control in stressful situations and strength of self-efficacy beliefs are strong predictors of academic achievement (Linnenbrink \& Pintrich, 2003; Perry et al., 2007). Lang (1985) posits that emotions are stored in memory as a series of propositions accessed by information processing mechanisms. When information is received that matches the stored propositions, particular emotions are evoked. Full emotional response is more likely with complete matches, but limited emotional response can be accessed with partial matches. This suggests that if modification of some of the propositions can be made, then the emotional response might be attenuated. Lang (1985) also suggests that emotional expression lies along three dimensions: arousal; from low arousal to high, valence; from unpleasant to pleasant, and the degree of control.

The environment in which Western style outdoor pursuits are undertaken has been found to be highly stress-inducing (Bunting et al., 2000; Ewert, 2014). This is particularly so for white-water kayaking where there are perceived and actual risks involving capsizing and a high incidence of physical injury (Bunting et al., 2000; Fiore \& Houston, 2001), thus the activity must be carefully managed. Stress can be viewed as a relationship ('transaction') between individuals and their environment, where the demands exceed the available coping resources (Lazarus \& Folkman, 1986). This points to two processes within a person in its environment: cognitive appraisal and coping. Lazarus and Folkman's (1984) model of stress appraisal and response shows that short-term outcome of stressors can result in positive or negative feelings. Stress leads to physiological activation (arousal); the individual can perceive this arousal in either of two directions, positive affect (excitement) or negative affect (anxiety) (Burton \& Naylor, 1997). A relationship between anxiety and arousal has been found, showing that high physiological arousal with high cognitive anxiety will lower performance (Hardy \& Parfitt, 1991; Krane, 1992). Some authors would suggest that participants can flip from one emotional state to another with no change in physiological arousal but only in somatic perception (Apter, 1982). Summarizing, how a student or participant experiences or interprets their arousal (as arousal, anxiety, fear, or excitement) can influence the person's experience and the learning potential in any given stressor-filled environment.

Some aspects of the white-water kayaking participant experience have been researched, such as kayakers' experience of flow (Jones et al., 2000) and female white-water kayakers' experiences related to fear, confidence and competence (Dingle et al., 2006). Other research in this field has focused on injuries/medical perspectives (Fiore \& Houston, 2001; Kizer, 1987; Murdoch \& Kelly, 2018), place attachment for white-water recreationists (Bricker \& Kerstetter, 2000; Kainzinger et al., 2018), and participation and involvement in white-water kayaking (Ewert et al., 2013; Schuett, 1993; Whiting et al., 2011). Research on how novice white-water kayakers experience emotions while learning, as well as the tools developed to measure this, needs to be undertaken and would make a valuable contribution to the outdoor education field in Scandinavia and other Western countries. This would provide instructors and leaders 
with a better understanding of the participant experience and their role in counteracting its negative effects.

In a gender perspective, the outdoor adventure environment is stereotypically seen as male dominated (Godtman Kling et al., 2020; Kennedy \& Russell, 2020), although we see women's participation increasing (Outdoor Foundation, 2020). Literature and research into gender has also developed, looking into gender role socialization, participant rating and programme planning, together with gender differences in outdoor experience and risk taking (Neill, 1997; Warren, 2002, 2016). Gender differences were found throughout an outdoor education programme with females consistently reporting higher levels of anxiety, where social fear was higher than physically based fear (Young \& Ewert, 1992). However, Chang et al. (2019) found no gender differences in stress levels of college age students, in short-term outdoor programmes. However, in general, little research literature exists on white-water kayaking, especially when related to gender.

The aim of this study was to explore outdoor education students' emotions 'in the moment' during an educational white-water kayaking day with a focus on how and why emotions change, their relationship to gender and the pedagogical implications.

The research questions were:

1) How do novice paddlers experience excitement during an educational whitewater (if possible) kayaking trip?

2) How do novice paddlers experience anxiety during an educational white-water kayaking trip?

3) How do novice paddlers experience arousal during an educational white-water kayaking trip?

4) Can causal factors be established for the changes in emotional state?

5) Can sex differences be detected in novice paddlers' experience of emotion (feeling excited, anxious, and aroused) during an educational white-water kayaking experience?

Of the available and validated measures of anxiety, the CSAI-2 (Martens et al., 1990) is reported to take up to ten minutes to complete when the parameter it measures is in a constant state of flux, and is arguably not measuring anxiety at all. At the other end of the scale, the Anxiety Thermometer (Pijpers et al., 2003) is very quick to complete, but is simplistic and lacks any detail of the nature of the anxiety state reported. The challenge of accurately measuring participants' experience of their emotions in the natural environment of a kayaking programme using a timely non-invasive tool is discussed in this study.

\section{Method}

We applied several methods to explore the participants' experiences, closed questions analysed with statistics and open-ended questions analysed qualitatively. By blending 
the approaches, the quantitative data are explained by the qualitative data and vice versa, providing richer data as a basis for informed conclusions.

\section{Participants and setting}

Participants in this study were students from two outdoor programmes in higher education, one group at university and one at college level, both based in Auckland, New Zealand. Fifty-eight students agreed to participate. The university group consisted of 14 female and 18 male participants, aged 18-30 years old. The college group consisted of 13 female and 13 male participants, all aged 17 . The overall gender distribution was 27 females and 31 males. Table 1 shows participant characteristics.

Table 1. Characteristics of participants

\begin{tabular}{lcccc}
\hline Group & M age $(\boldsymbol{S D})$ & Male & Female & Total \\
\hline University & $21(3.1)$ & 18 & 14 & 32 \\
College & $17(0)$ & 13 & 13 & 26 \\
\hline Total & $19(3)$ & 31 & 27 & 58 \\
\hline
\end{tabular}

Abbreviations: $M=$ mean, $S D=$ standard deviation

Students taking a kayaking programme as part of their university diploma or outdoor education course at college were invited to participate in this study as they follow identical programmes at the same venues with mostly the same instructors and organiser. Within the two groups, the students were familiar with each other as they had worked together across several other outdoor activities in other parts of their outdoor education programme. The programme aimed to provide the students with kayaking skills and knowledge of themselves and the environment. It was implemented by qualified male and female instructors from the New Zealand Outdoor Instructors Association. The white-water programme is described in Table 2.

Table 2. Description of the kayaking programme

\begin{tabular}{lll}
\hline \multicolumn{1}{c}{ Day 1 } & White-water kayaking programme & \multicolumn{1}{c}{ Day 2 } \\
\hline - Training on basics in heated & \multicolumn{1}{c}{ Drive to river } & Day of data collection \\
pool & - Boat fit and safety instructions & ・ Breakfast and camp time \\
- Training on wet exit & - Kayaking on grade 1 river & (site 1, Rest lodge) \\
- Introduction and training on & - Set-up camp/dinner & ・ Boat fit and getting ready \\
rolling & - Discussions and debrief & (site 2, Rest riverbank) \\
- Introduction and training on & & - Kayaking on river grade I-II \\
different rescue techniques & & (site 3 and 4, On water) \\
& & - Lunch (site 5, Recovery) \\
\hline
\end{tabular}


"... the thought that I could flip and die today made me feel anxious"

\section{Ethical considerations}

This research was approved by the Auckland University of Technology Ethics Committee on 30 September 2013, Reference number 13/235 AUTEC. The researchers provided oral and written information about the study to the students. Written consent was obtained from all participants in this study. Participants were informed that they could withdraw from the study at any time without consequences and were assured of confidentiality.

\section{Data collection}

Data were collected on the third day of the kayaking programme that involved paddling $10 \mathrm{~km}$ on a grade I-II river in small groups. Participants were given a number code written on their hand with waterproof ink. The participants wrote this code on the questionnaires to ensure anonymity and enable tracking of answers across the day. They were again informed orally about the purpose of the study and the concepts of excitement, arousal and anxiety were explained. The questionnaire was given on five different occasions. Site 1, Rest lodge: In the morning, shortly after the participants woke up, Site 2, Rest riverbank: The participants were in their gear and ready to go on the river, Site 3, On water 1: Short break on the river, Site 4, On water 2: Just after the largest rapid at the end of the river trip and Site 5, Recovery: After a one-hour lunch break.

Data collection took place in a natural environment and in an educational context, and therefore involved certain constraints. The research aim was to disrupt the normal kayaking programme as little as possible and keep the natural environment of both the kayaking and the educational context authentic. To minimise impact, data collection was carried out in their normal breaks and questionnaires were not given to the participants until they needed to be filled out. The kayaking instructors were trained to help in the data collection, handing out questionnaires and collecting them at designated places. Prior to the trip, the instructors were given a written explanation about the study and how data should be collected, with descriptors of how excitement, anxiety, and arousal should be understood if participants asked during data collection. Further, researchers provided instructors with an oral briefing on the morning of data collection. A short questionnaire was developed, ensuring that participants were able to give answers easily and quickly, whilst requiring a minimum of material to accommodate the sometimes wet, cold and windy environment. All data were carefully and accurately typed in Microsoft Excel format.

\section{Measurements}

Excitement, anxiety, and arousal can be measured by a variety of methods, but perhaps the most relevant to this study is the self-report. This method gives insight into how the physiological changes and emotions are being perceived by the participant (physically). As emotional response is dependent on the person's interpretation via 
the relevant hedonic tone and matching of stored propositions of those feelings, it can be argued that this method has greater relevance than any quantitative biological marker. Before the commencement of the study, excitement, anxiety, and arousal were described to the participants and examples were given to aid understanding of the terms. Excitement was described for the participants as a positive feeling, like buzzing, eagerness, enthusiasm, or exhilaration. An example is the way a child can feel on Christmas Eve. Anxiety was described as feelings of worry, fear, or uneasiness. When one is anxious, one is very concerned or worried about what may happen or has happened. It is a general negative feeling of concern about something real or imagined. Arousal was described as how busy and alert one's mind and body are. If a person is really ready to do something, that person is highly aroused. A feeling that one's heart is beating quickly, sweating and a focused mind are all signs of high arousal. Feeling sleepiness (but not tiredness) and relaxation are signs of low arousal.

\section{Instrument}

Participants' perceptions of how they experienced excitement, anxiety, and arousal were measured through a questionnaire we developed to specifically fit the natural environment of white-water kayaking: the Kayaking Emotion Thermometer (KET) (Appendix 1). This instrument was designed to give a simple to administer 'snapshot' of the emotional state of the participant 'in the moment', but also to provide a deeper understanding of the participants' lived experience. Due to ethical constraints, it had to minimise disruption to the participant's programme. Participants were asked to indicate on each of three Likert-type scales their perceived level of excitement, arousal and anxiety. A continuum was used to avoid participants matching perceived feelings with those of peers. In the printed version the scale is $10 \mathrm{~cm}$ so that the response can be converted to a numerical value for analysis.

A deeper understanding of the participants' emotional state and the direction of their state of affect was derived from the open-ended question, "Please state what makes you feel the way you do". This phrase was used to enable participants to comment on the widest possible range of perceived causation (internal, environmental, social and facilitation) without any leading bias.

\section{Analysis}

SPSS 26.0 was used for statistical analysis (Chicago, IL, USA), with a significance level of 0.05. All participants were included even though some did not have a complete data set. This could be a source of bias, although an analysis can be considered valid provided the data are missing at random, thus the data set will still be representative. A Little's MCAR test (Little, 1988) showed that the data were missing at random, hence we report on the original dataset with all participants included. Participants' stated excitement, anxiety, and arousal are reported as means with standard deviation. Independent sample t-tests were used to compare means and a 
one-way between-subjects ANOVA with Bonferroni corrections was used to analyse changes over the five time points.

\section{Analysis of qualitative data}

This was guided by thematic analysis (Braun et al., 2016) and conducted with a reflective inductive approach. Thematic analysis was appropriate as it can show patterns of shared meaning. It uses reflexivity as an essential aspect and the subjectivity of the researcher is a resource rather than a potential threat (Braun \& Clarke, 2019). The analysis consisted of the following five steps (Braun \& Clarke, 2019; Braun et al., 2016):

1) Familiarising oneself with the data: The written responses from all sites were initially read to gain an overall impression and become familiar with their content.

2) Generating initial codes: The text passages were then organised into the five sites, and each site then became a source of a thematic analysis. At each site text was organised into codes representing shared meaning, e.g. 'fun' and 'competence' were codes developed when analysing site 4 .

3) Searching for themes: The codes were organised into potential themes and subthemes.

4) Reviewing themes: The themes were checked to ensure that they represented the content of the codes.

5) Defining and naming themes: The themes and subthemes were revisited, analysed, and redefined. The themes aimed to describe the essence of the participants' experience at each site.

We have provided readers with several passages to inform them of their nature and depth, while allowing them to share the participants' experiences. Data from each data site consisted of 42-50 written responses, giving 229 short answers in all.

\section{Results}

Excitement, anxiety, and arousal during the kayaking day

Participants' reported feelings of excitement, anxiety, and arousal during the kayaking day are presented in Figure 1.

A one-way between-subjects ANOVA showed significant changes in excitement during the kayaking day, $F(4,188)=18.53, p<.001$. The post-hoc test revealed that the participants' scores of excitement significantly increased from Rest lodge to Rest riverbank $(p=.009)$. Further, they increased significantly between On-water 1 and On-water $2(p<.001)$, followed by a significant fall in excitement between On-water 2 and Recovery $(p<.001)$. This shows that excitement steadily increased during the kayaking day and only dropped when the trip ended, but was still relatively high.

The one-way between-subjects ANOVA showed significant changes in anxiety during the kayaking day, $F(4,188)=14.25, p<.001$. The post-hoc test showed no 
significant change in feeling anxious between Rest lodge, Rest riverbank, On-water 1 and On-water 2. Anxiety was significantly lower at Recovery than all other sites $(p<.001)$.

A one-way between-subjects ANOVA showed significant changes in arousal during the kayaking day, $F(4,184)=25.8, p<.001$. The post-hoc test revealed that the participants' scores of arousal significantly increased between Rest lodge and Rest riverbank $(p<.001)$. Further, arousal increased significantly between On-water 1 and On-water $2(p<.001)$, followed by a significant decrease between On-water 2 and Recovery $(p=.012)$. The means and standard deviation are presented in Figure 1.

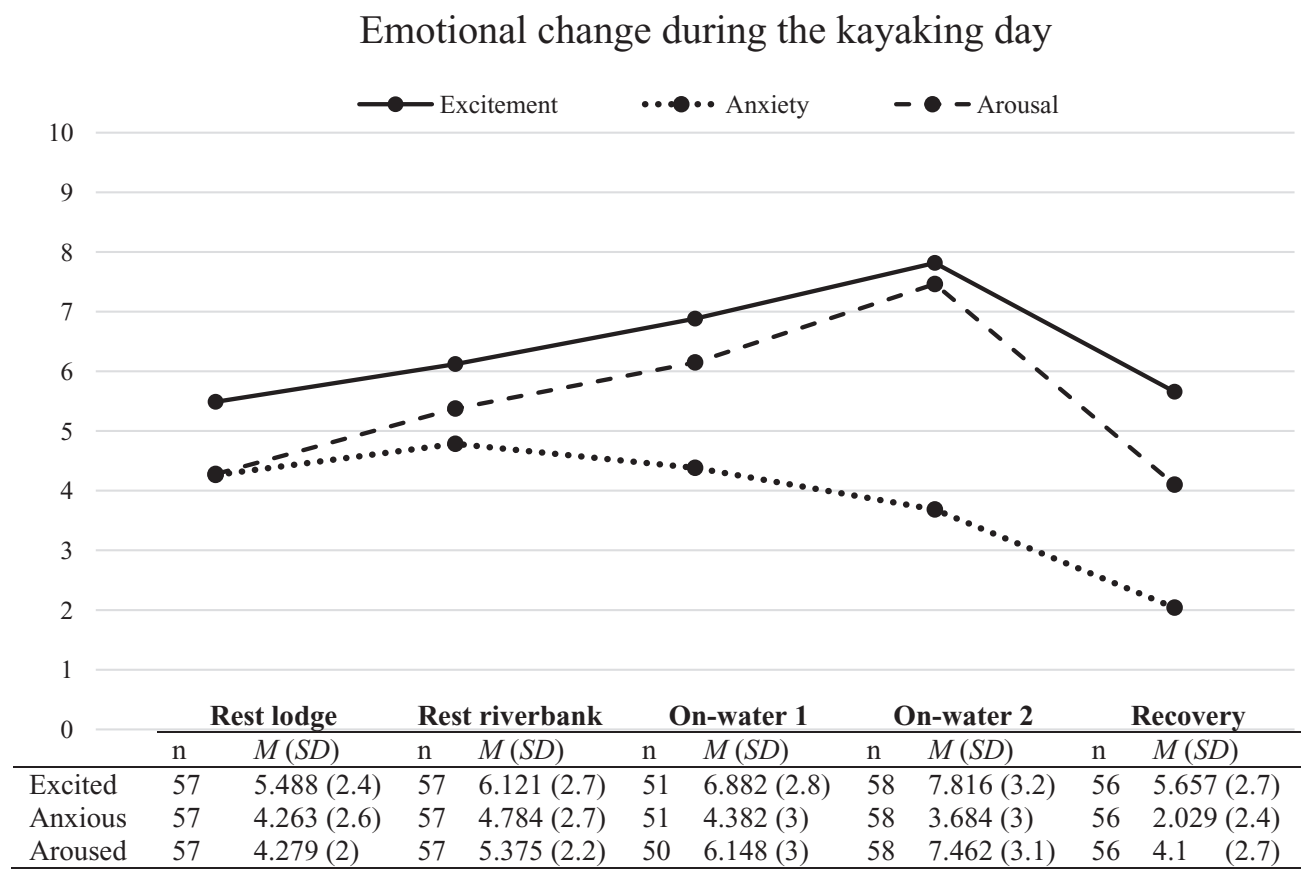

Figure 1. Excitement, anxiety, and arousal changes over time, table showing means and standard deviation

Abbreviations: $M=$ mean, $S D=$ standard deviation

Participant scores of excitement were significantly higher than arousal at Rest lodge (confirmed by a paired sample t-test, $p<.001$ ) with no differences found at the other sampling sites. Excitement is significantly higher than anxiety at all sites (confirmed by a paired sample t-test, at Rest lodge $p=.011$, at Rest riverbank $p=.014$, On-water $2 p<.001$, On-water $2 p<.001$ and Recovery $p<.001)$. Anxiety is significantly lower than arousal (and excitement) at On-water $1(p=.002)$, and On-water $2(p<.001)$ and Recovery $(p<.001)$. 


\section{Perceived emotions over time by gender}

Figure 2 presents male and female participants' reported feelings during the kayaking day. Although female participants reported consistently higher levels of anxiety than their male counterparts did, this difference did not reach statistical significance ( $p=.062$ at site 3, On-water 1). Perhaps a larger study showing similar trends would meet the statistical threshold. Other emotions showed even closer correlation between males and females.
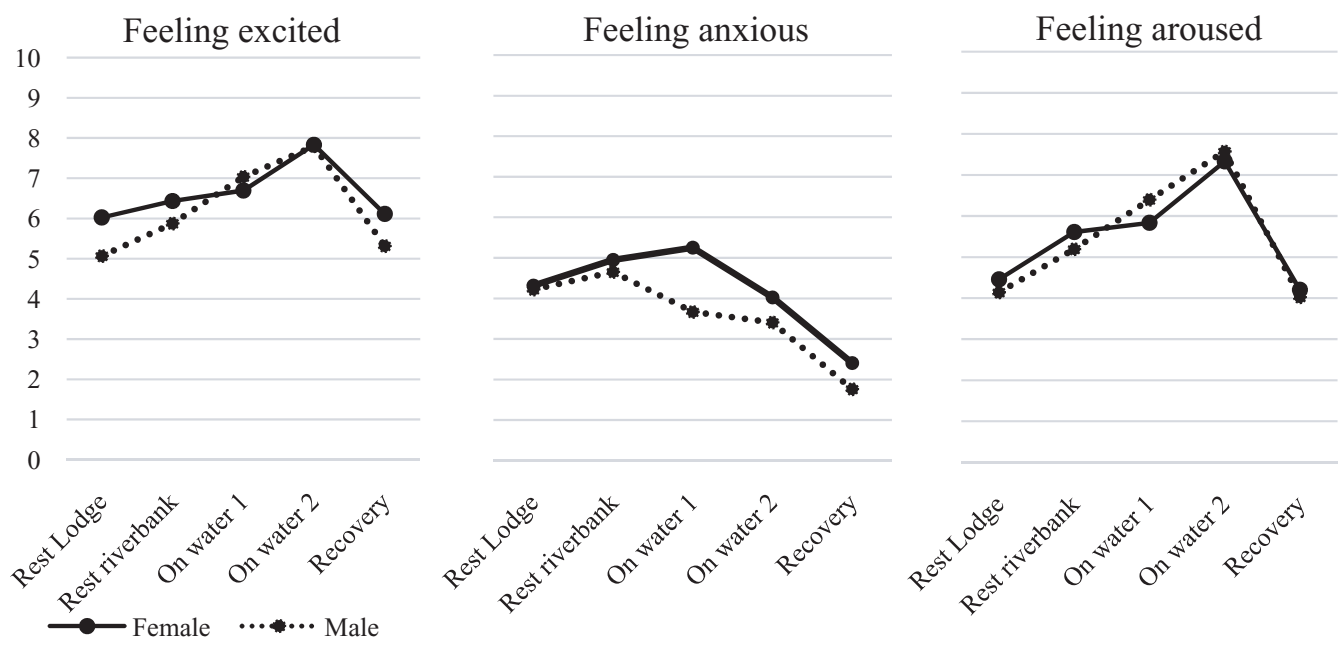

Figure 2. Male and female mean scores of excitement, anxiety, and arousal

Results from thematic analysis of participants' answers to the open question "Please state what makes you feel the way you do"

Identified themes and subthemes for the five sites are presented and described below in Table 3. Each theme describes the essence of the participants' shared experiences at each site. Participants' quotes exemplify the findings, and we added their scale-reported emotions to enhance our understanding of the level of reported experience of emotions. At each theme, we look across the data, letting the different data complement each other to deepen our understanding of the participants' emotional experience.

Figure 3 (below Table 3) presents data for one male participant. This exemplifies the findings, namely that participants across the day report high levels of excitement, anxiety, and arousal, indicating that this is a stressful experience and environment. It shows that negative emotions and expectations are present before starting the activity, however once taking part in the activity, the high arousal is in a positive direction and anxiety is lowering. Overcoming fear and anxiety, personal learning and development occur while perceived competence increases. Of note are the lasting effects of excitement (afterglow) and the steady decline in anxiety throughout the day. 


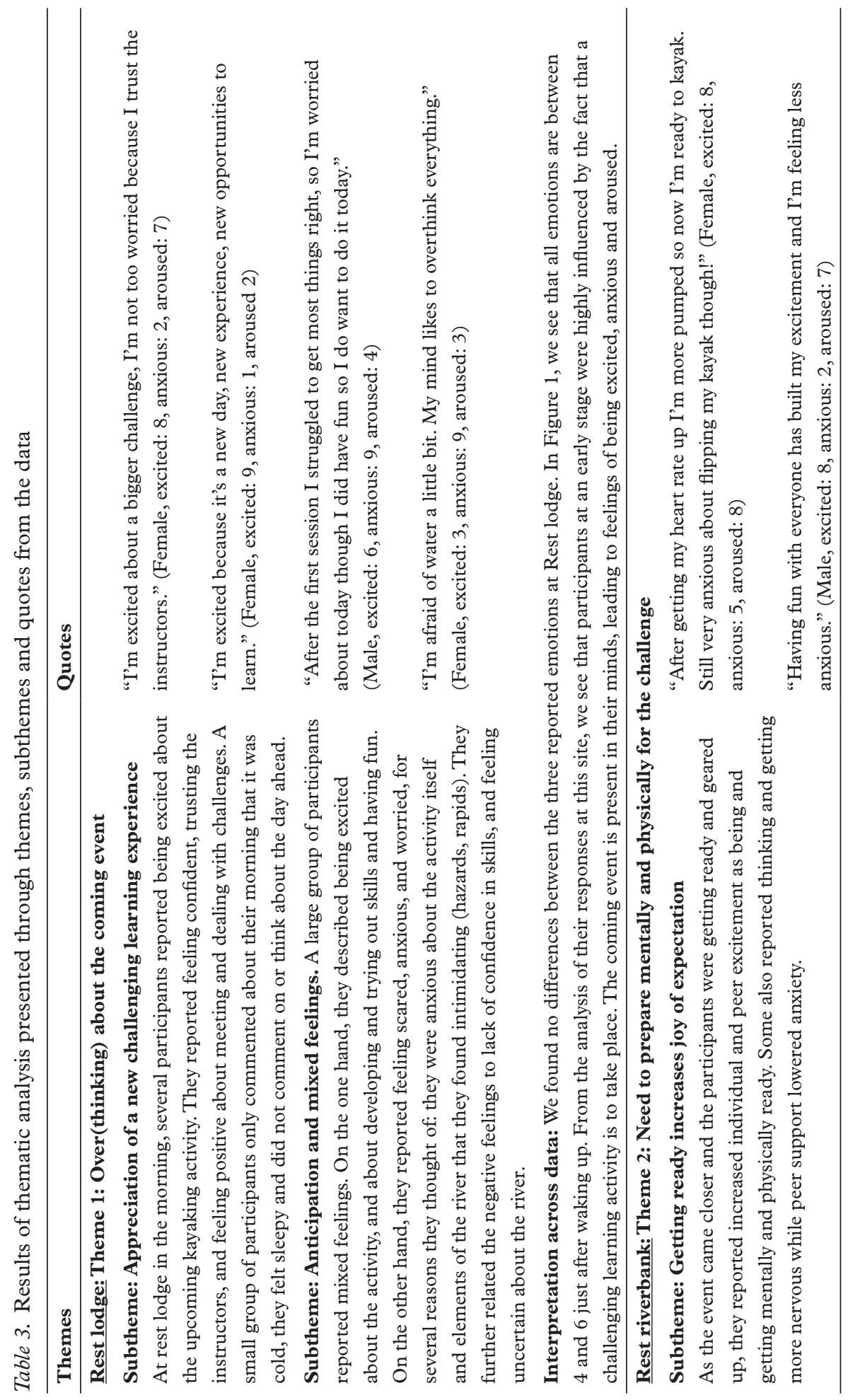


"... the thought that I could fip and die today made me feel anxious"

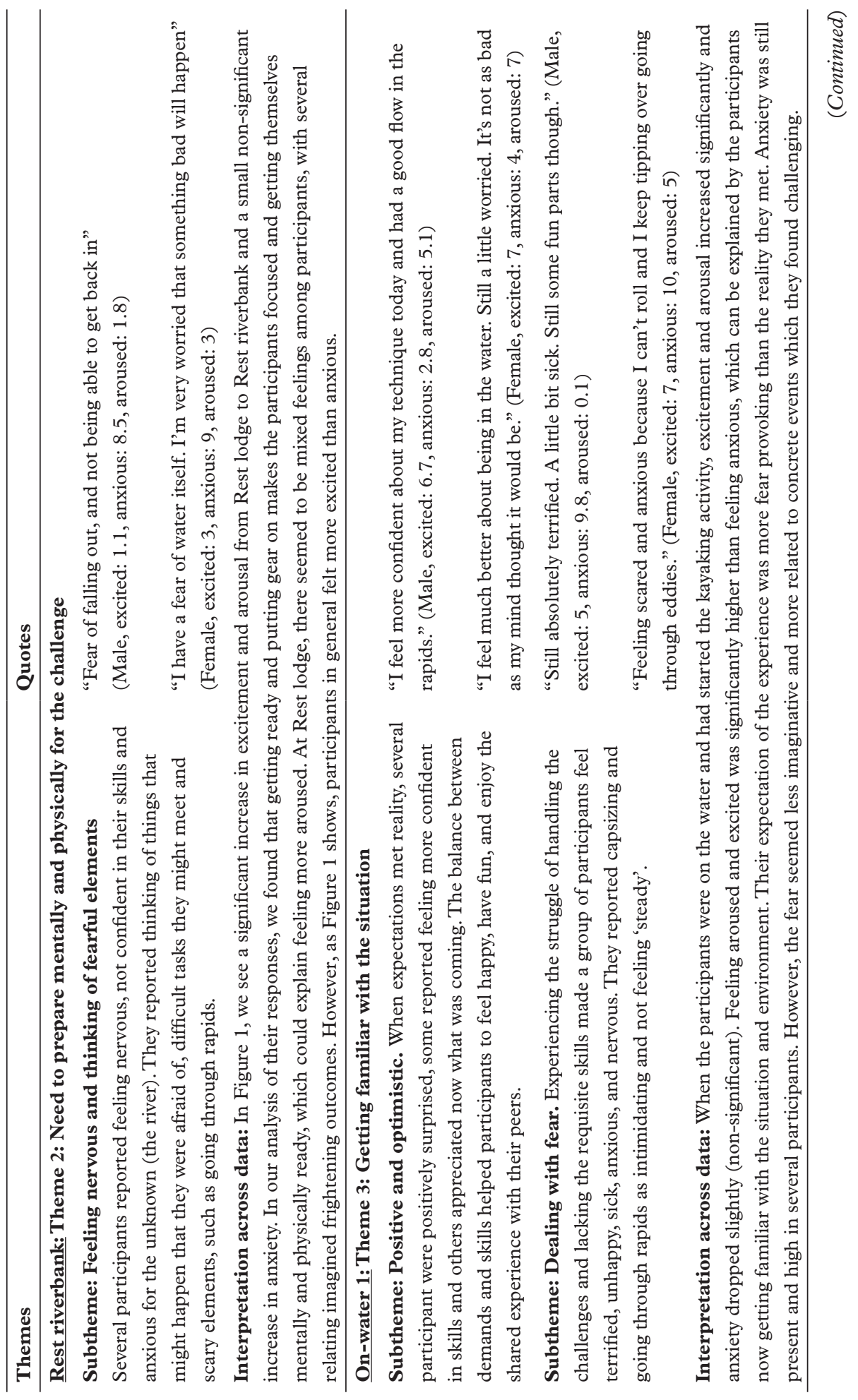




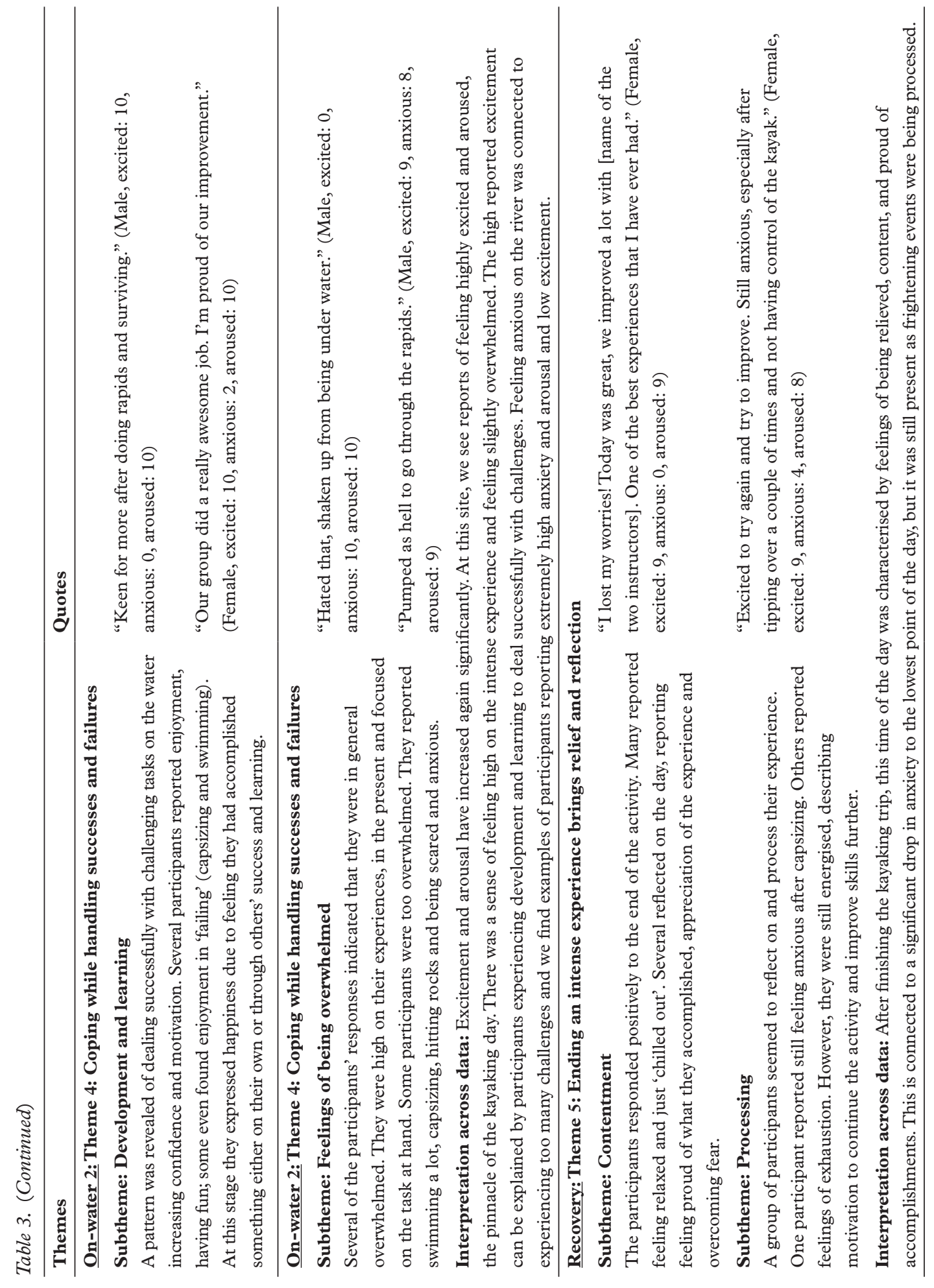




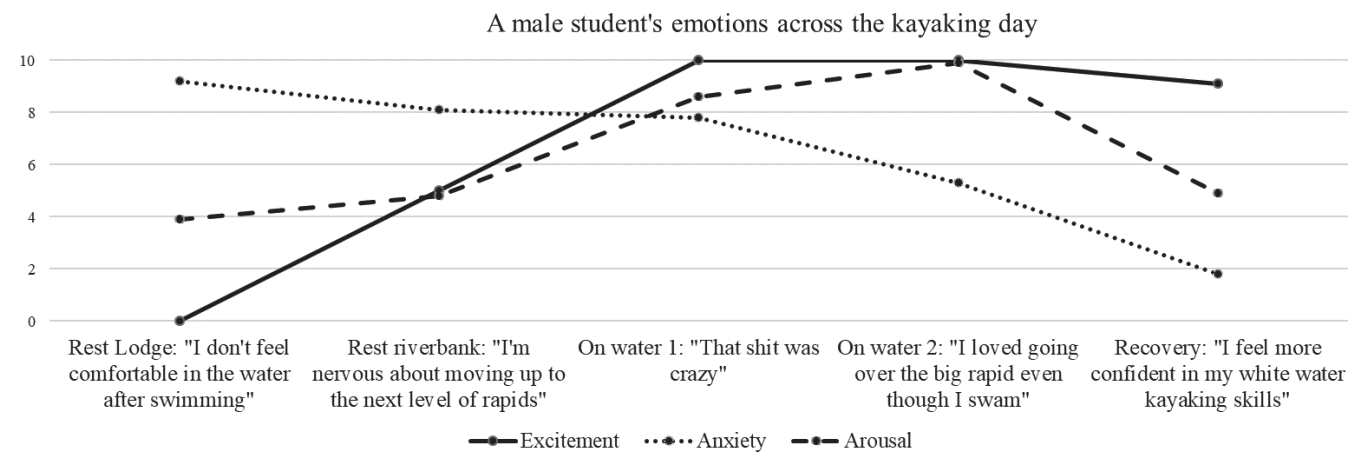

Figure 3. Example of one male participant's emotional experience of the kayaking day

\section{Discussion}

The participants' experience of emotions while learning white-water kayaking in a natural setting have been explored through a blend of approaches capturing the participants' self-reported experience 'in the moment' across an educational kayaking day. The results suggest that the participants in our study find learning whitewater kayaking to be an intense process and experience, with strong emotions. This is related to the experience of white-water kayaking as an activity that sets certain requirements on the individual and the experience of the river and its features as sustained and unpredictable, yet a desirable challenge to take on.

\section{Mastery experience}

The changes that we see over the duration of the kayaking day in Figures 1 and 2 can be explained by several branches of research. We see that self-reported arousal and excitement rise as anxiety falls over the time the participants were preparing for the trip, and on the water tackling the rapids. Bandura's (1977) theory of self-efficacy relies on four sources of information (antecedents) on which to base judgement. The participants will be highly aware of these during the kayaking experience: their level of 'physiological arousal', seeing their peers succeed or fail (vicarious experience), their own previous success or failure 'mastery experience', and their instructor's and peers' 'verbal persuasion'. To some extent, greater experience will strengthen judgements of self-efficacy but only if the experiences are positive, successful and nurturing, thus fulfilling the conditions for optimal learning environments of Davis-Berman and Berman (2002) and Dingle et al. (2006). The strength of the social environment, the skill of the instructors, and the design of the programme interact with the participants' skills development to enable feelings of control and personal mastery which account for anxiety waning and excitement increasing. We see increasing levels of self-reported arousal, which would be congruent with the increasing technical difficulty of the rapids, and would be explained by Apter's (1982) reversal theory 
where high arousal can be perceived as anxiety (at the start of the day) or excitement, with greater judgements of efficacy for the skills required. This leads to pleasant feelings and exhilaration, with increasing perceptions of personal mastery for the skills required. The physical challenge set for participants by the rapids of a particular river on a given day are relatively fixed; however, the participants' skill in manoeuvring their kayak are more subject to change (due to ongoing practice and ever greater experience). In this context, the pleasant sensations of personal mastery (Zaichkowsky \& Baltzell, 2001) occur when the skill level has caught up with the demands placed on the participant by the environment. However, the emotional response of the participant is in even greater flux, dependent on the participants' interpretation of the level of challenge, their perception of the required skill level as well as their physical, physiological and cognitive arousal response. Indeed the hedonic tone that they ascribe to their individual set of antecedents highly influences their emotional state (Apter, 1982). This would suggest that increased lived experience of the river and ongoing practice of skills increased their judgement of self-efficacy (Bandura, 1977) for those skills at a greater rate than the increased challenge set by the technical difficulties of negotiating the rapids. It is suggested that only under well managed, appropriate activities, does this lead to an increased hedonic tone and strengthened judgements of self-efficacy (mastery experience), and greater perceptions of control (Folkman \& Lazarus, 1988), thus leading to reports of increasingly excited emotional responses even during increasing arousal responses through the day.

\section{Gender differences}

Participant self-reports of physiological arousal and excitement showed a very similar pattern over the kayaking day, generally rising to the point on the river where the most difficult rapids were (On-water 2). Differences in the reported levels of anxiety between the male and female participants on the river did not quite reach statistical significance. However, a larger study or splitting the participant group along a gender continuum may have revealed a significant difference. This data is in line with other gender-based anxiety studies (Puskar et al., 2009), where females reported higher levels of anxiety than males. It has been suggested that females may be more inclined to reveal a true record of their feelings, whereas males may suppress their reporting as befitting of their burgeoning masculinity. However, the value of the qualitative question, as used in this research, suggests that in this study, the males and females represented their own level of anxiety accurately. It is interesting to note that the effect of anxiety on enjoyment and learning is purely based on an individual's perception of that somatic anxiety and not on a particular biologically measured marker.

Although white-water kayaking is seen as a male-dominated activity, nearly half of the participants in our study were female. It has been argued that gender differences are less often seen because women who choose to participate in outdoor education programmes may be a self-selected group, who have higher ideals of self-conceptualisation and are more motivated towards personal development than 
their male counterparts. It suggests that females show greater change than males because they are physically and psychologically more challenged when they are forced into a different and unfamiliar role (Neill, 1997). One of the few studies exploring female perspectives in white-water kayaking found that women favoured learning to kayak on a trip down the river as a journey rather than skill acquisition and practice on a single river feature, as some women favour a task-oriented environment that sets non-competitive standards (Dingle et al., 2006). In addition, females seek skilled coaching from their instructor and "not just being a good paddler" (Dingle et al., 2006). This could indicate that the form of the investigated kayaking programme works well for females. The study by Dingle et al. (2006) concludes that instructors would do well to pay attention to and address the fears felt by female paddlers, as some female paddlers reported being uncomfortable performing in front of skilful peers. This study concludes that social fear can be a powerful inhibitor of risk taking and learning, affecting confidence and hence competence, most noticeably in female paddlers. Social factors could affect females' higher scores of feeling anxious, but our data does not provide such evidence. We argue that paying attention and addressing fears is important to both male and female participants learning white-water kayaking.

\section{Linking written responses to scores of emotion}

An interesting finding is that the participants experienced most anxiety before going on the water. This seems to be driven by their expectations of what might happen, overthinking and imagining events, as a way of preparing themselves mentally for the forthcoming experiences (Themes 1 and 2). Participants in our study reported some level of anxiety throughout the day, highest at the beginning, when they were struggling with what is real and what is perceived risk with no experience to guide them. However, dealing successfully with challenging tasks as they go through the day strengthens confidence and motivation, while giving them a sense of accomplishment, personal mastery and reality (Themes 3 and 4). Overcoming challenges led the participants to a process of reflection about themselves and their capabilities, leading to feelings of contentment and pride as they absorbed the intense experience (Theme 5). The fact that the participants were facing actual white-water rapids for the first time, as their previous experience had been in a pool or flat water, could explain the high anxiety at the start and its decrease once the participants had time to settle into how rapids affect the movement of the kayak and use and gain confidence in techniques taught on still water in a new context. Other causes may be found in the participants settling into the social structure enforced upon them, as found by Witman (1995) and Orson et al. (2020). We see in Theme 4 that the participants were settling in with their new kayaking groups: "Our group did a really awesome job. I'm proud of our improvement." They also felt that they trusted their instructors: Theme 1: "I'm not too worried because I trust the instructors." Theme 5: "Today was great, we improved a lot with [name of the two 
instructors]", as Humberstone and Stan (2011) illustrate the importance of the instructor-participant relationship.

Similar results were found in a recent study, reporting that learning in an adventure education programme came from an active process of grappling with difficult challenges, including pain and emotional obstacles (Orson et al., 2020). Successfully overcoming these challenges led the participants to have reflective insights, discoveries and realisations about themselves and their capabilities (Orson et al., 2020). Interestingly, white-water kayakers may have positive experiences even when their abilities are exceeded by the difficulty of the river (Jones et al., 2000). We do find supporting examples in our data (in Figure 3), where participants' fear turned into reality; however, even though capsizing and swimming, the participants report positive feelings and increased confidence. Perhaps even though things went wrong, the reality was not as bad as their prediction, further increasing confidence, lowering anxiety, and altering their hedonic tone towards excitement and wellbeing.

Scant research suggests that too high perceived risk and anxiety in adventure programmes are detrimental, thereby challenging the historically situated assumption of a 'fear for all' approach (Reed \& Smith, 2021). Reed and Smith (2021) found that those outdoor adventure education participants who were not able to successfully interact with their fears perceived feelings of terror, often resulting in them attending as observers and/or dropping out of the programme. This indicates a large discrepancy between the fear that the facilitators suggested to the participants, and how participants actually experienced that fear. This supports Davis-Berman \& Berman's (2002) notion that participants should feel safe, secure and cared for, and therefore one should work within, or in close proximity to, participants' comfort zones. Educators in white-water kayaking, or other intense or stressful environments, can benefit from a better understanding of when and why participants tend to feel anxious, and as Reed and Smith (2021) found, fear isolated and marginalised participants who were unable to successfully interact with that fear. Our KET tool offers facilitators a timely method of monitoring participant experiences to enable client emotions to be managed, and activities regulated to nurture positive learning outcomes. We believe our study provides a substantial contribution by showing that the time leading up to a demanding adventurous learning activity directly affects the participants' emotional experience and learning outcomes. Thus (over)thinking of the coming event (Theme 1) and need to prepare mentally and physically for the challenge (Theme 2) represent a period that is perhaps underestimated, a time for instructors to recognise and address unnecessary anxiety and fear. This is, however, also evident towards the end of the activity, as several participants in our study reported concerns during the activity, dealing with fear (Theme 3), coping and handling successes and failures (Theme 4). Ending the intense experience brings relief and reflection (Theme 5), where both excitement and anxiety are still present, thus representing an opportunity where instructors could actively engage and help facilitate the participants to process 
their intense learning experiences. This would give merit to the educator's full use of these times to pre-brief and de-brief the experience to fully anchor the activity within the educative process.

\section{Methodological considerations}

Using a mixed method technique strengthens the validity of the research by triangulation. Physiological arousal markers have been widely reported to show little direct correlation with each other (Haneishi et al., 2007; Jones \& Hardy, 1990). It has been suggested that individuals differ in their response to stressful situations and that therefore their arousal is expressed in somewhat differing ways (Hanin, 2000). Bailey et al. (2017), in studying adventure activities, concluded that self-reported measures of arousal in general agreed with objective data, meaning that the somatic measure as used in this study is very likely to be 'as accurate' as more invasive and time-consuming evaluations of a spectrum of biological markers. This may be due to individuals assessing their state from a blend (their own individual mix) of physiological markers and social cues as predicted by Lang (1985). This would concur with Hanin's (2000) notion of individual zone of optimum function, and that individuals can perceive their own individual state better than direct measurement of physiological arousal markers. The measurement, via a somatic arousal and emotion tool such as used here (KET), may give the best overall indication of arousal and emotion, and most importantly, as it affects the participant 'in the moment', more accurately than other more direct and less timely measurements could do. The questionnaire provides a method that works well in outdoor education research, as it requires few resources and allows data collection from a relatively large number of participants with minimum interference to the educational programme, capturing the phenomenon in its natural setting. Emotions can be fleeting, so capturing them 'in the moment' is imperative. There is always a gap between the participant's experience and reporting. By using the KET at several time points we have minimised this gap. Future additions to the KET could be considered, such as overall feeling of happiness and confidence in skill level. However, it should continue to be short to maintain its purpose of giving a nonintrusive snapshot. The written responses from participants were short and informative, but could have limited the depth of the thematic analysis, perhaps providing a summary of the data rather than conceptualised themes.

\section{Limitations and future research/recommendations}

A larger study may reveal a significant difference between male and female perceptions of anxiety in learning white-water kayaking. The way white-water programmes are structured and facilitated may influence the participants' experience as affected by the social setting. In addition, further research should explore how the participants processed and made sense of their intense experience, what meaning and reflections they made about their experience and themselves, as well as their perception of the 
causal factors. Improvements in wearable digital recording devices could be explored to narrow the experience-reporting gap with more frequent data collection presenting a fuller picture of the lived experience.

\section{Concluding remarks}

In this study, we developed a tool to capture novice white-water kayakers' emotions 'in the moment' on an educational kayaking day. We found the river to be a stressful environment provoking intense emotions. Anxiety and fears were present during the whole day, highest before going on the river. Being on the river induced high excitement and arousal while grappling with the imposed challenges, successfully and non-successfully. Instructors should reduce and address unnecessary anxiety and fear and further question the approach of fear for all to learn and grow. This tool can be used to accurately provide a window into the participants' experience of an adventure activity and therefore inform programme design and instructors' teaching approach. The data can also be used as a rich source from which participants can reflect and learn both in the physical and mental selfregulation domains.

\section{Acknowledgments}

We are grateful to the programme staff and instructors who invested their time and energy to support this study and the programme participants for being willing to share their personal experiences for this research.

\section{Author biographies}

Sabrina Krogh Schmidt is employed at the Department of Sport, Physical Education and Outdoor Studies, Faculty of Humanities, Sports and Educational Science, University of South-Eastern Norway. Her educational background is within sports, physical activity and outdoor education, and she is currently a PhD candidate.

Dr. Matt Barker is a senior lecturer for Auckland University of Technology in New Zealand. He has been teaching and leading in the outdoors for over 35 years. He still enjoys the outdoor life, introducing others to the white-water environment and training the next generation of outdoor educators.

Jennifer Byrne holds a masters in cognitive neuroscience from Aston University in United Kingdom. She undertook a year-long placement at Auckland University of Technology as part of her psychology bachelors degree where she co-developed the questionnaire and helped with data collection in for this presented study in novice white water kayaking. 
"... the thought that I could flip and die today made me feel anxious"

\section{References}

Aas, Ø., \& Onstad, O. (2013). Strategic and temporal substitution among anglers and white-water kayakers: The case of an urban regulated river. Fournal of Outdoor Recreation and Tourism, 1-2, 1-8. https://doi.org/ 10.1016/j.jort.2013.04.002

Apter, M. J. (1982). The experience of motivation: The theory of psychological reversals. Academic Press.

Bailey, A. W., Johann, J., \& Kang, H. K. (2017). Cognitive and physiological impacts of adventure activities: Beyond self-report data. Fournal of Experiential Education, 40(2), 153-169. https://doi.org/10.1177/ 1053825917701250

Bandura, A. (1977). Self-efficacy: Toward a unifying theory of behavioral change. Psychological Review, 84(2), 191-215. https://doi.org/10.1037/0033-295X.84.2.191

Bates, R., \& Khasawneh, S. (2007). Self-efficacy and college students' perceptions and use of on-line learning systems. Computers in Human Behavior, 23(1), 175-191. https://doi.org/10.1016/j.chb.2004.04.004

Bauml, K., \& Kuhbandner, C. (2009). Positive moods can eliminate intentional forgetting. Psychonomic Bulletin E Review, 16(1), 93-98. https://doi.org/10.3758/PBR.16.1.93

Beames, S., \& Brown, M. (2016). Adventurous learning: A pedagogy for a changing world. Routledge.

Berry, J. M., \& West, R. L. (1993). Cognitive self-efficacy in relation to personal mastery and goal setting across the life span. International fournal of Behavioral Development, 16(2), 351-379. https://doi.org/ $10.1177 / 016502549301600213$

Braun, V., \& Clarke, V. (2019). Reflecting on reflexive thematic analysis. Qualitative Research in Sport, Exercise and Health, 11(4), 589-597. https://doi.org/10.1080/2159676X.2019.1628806

Braun, V., Clarke, V., \& Weate, P. (2016). Using thematic analysis in sport and exercise research. In B. Smit \& A. C. Sparkes (Eds.), Routledge handbook of qualitative research in sport and exercise (pp. 191-205). Routledge.

Braunstein-Bercovitz, H. (2003). Does stress enhance or impair selective attention? The effects of stress and perceptual load on negative priming. Anxiety, Stress, and Coping, 16(4), 345-357. https://doi.org/10.1080/ 10615800310000112560

Bricker, K. S., \& Kerstetter, D. L. (2000). Level of specialization and place attachment: An exploratory study of whitewater recreationists. Leisure Sciences, 22(4), 233-257. https://doi.org/10.1080/01490409950202285

Brown, M. (2008). Comfort zone: Model or metaphor? fournal of Outdoor and Environmental Education, 12(1), 3-12. https://doi.org/10.1007/BF03401019

Bunting, C. J., Tolson, H., Kuhn, C., Suarez, E., \& Williams, R. B. (2000). Physiological stress response of the neuroendocrine system during outdoor adventure tasks. Fournal of Leisure Research, 32(2), 191-207. https://doi.org/10.1080/00222216.2000.11949913

Burton, D., \& Naylor, S. (1997). Is anxiety really facilitative? Reaction to the myth that cognitive anxiety always impairs sport performance. Fournal of Applied Sport Psychology, 9(2), 295-302. https://doi.org/ 10.1080/10413209708406488

Chang, Y., Davidson, C., Conklin, S., \& Ewert, A. (2019). The impact of short-term adventure-based outdoor programs on college students' stress reduction. Fournal of Adventure Education and Outdoor Learning, 19(1), 67-83. https://doi.org/10.1080/14729679.2018.1507831

Csikszentmihalyi, M. (2000). Beyond boredom and anxiety. Jossey-Bass.

Davis-Berman, J., \& Berman, D. (2002). Risk and anxiety in adventure programming. Fournal of Experiential Education, 25(2), 305-310. https://doi.org/10.1177/105382590202500209

Deane, K. L., Harré, N., Moore, J., \& Courtney, M. G. R. (2017). The impact of the project K youth development program on self-efficacy: A randomized controlled trial. Fournal of Youth and Adolescence, 46(3), $516-537$. https://doi.org/10.1007/s10964-016-0463-9

Dingle, P., \& Kiewa, J. (2006). Links between kayaking, fear, confidence and competence: Factors affecting women's participation in paddling in a tertiary outdoor education course. Fournal of Outdoor and Environmental Education, 10(1), 46-53. https://doi.org/10.1007/BF03400830

Endler, N. S., Speer, R. L., Johnson, J. M., \& Flett, G. L. (2001). General self-efficacy and control in relation to anxiety and cognitive performance. Current Psychology, 20(1), 36-52. https://doi.org/10.1007/s12144001-1002-7

Ewert, A., Gilbertson, K., Luo,Y. C., \&Voight, A. (2013). Beyond “Because it's there”: Motivations for pursuing adventure recreational activities. Fournal of Leisure Research, 45(1), 91-111. https://doi.org/10.18666/ jlr-2013-v45-i1-2944

Ewert, A. S. (2014). Outdoor adventure education: Foundations, theory, and research. Human Kinetics.

Eysenck, M.W., \& Calvo, M. G. (1992). Anxiety and performance: The processing efficiency theory. Cognition and Emotion, 6(6), 409-434. https://doi.org/10.1080/02699939208409696 


\section{S. K. Schmidt, M. Barker E F. Byrne}

Folkman, S. (1984). Personal control and the stress and coping process: A theroretical analysis. Fournal of Personality and Social Psychology, 46(4), 839-852. https://doi.org/10.1037/0022-3514.46.4.839

Folkman, S., \& Lazarus, R. (1988). Coping as a mediator of emotion. Fournal of Personality and Social Psychology, 54(3), 466-475. https://doi.org/10.1037/0022-3514.54.3.466

Fiore, D. C., \& Houston, J. (2001). Injuries in whitewater kayaking. British fournal of Sports Medicine, 35(4), 235-241. https://doi.org/10.1136/bjsm.35.4.235

Føllesdal, H. (1996). Psykiske faktorer ved veiledning/instruksjon av grupper [Psychological factors in guidance/instruction of groups] [Unpublished manuscript]. Norges Padleforbund (Norwegian Canoe Federation).

Godtman Kling, K., Margaryan, L., \& Fuchs, M. (2020). (In)equality in the outdoors: Gender perspective on recreation and tourism media in the Swedish mountains. Current Issues in Tourism, 23(2), 233-247. https:// doi.org/10.1080/13683500.2018.1495698

Gray, T., \& Piggott, F. (2018). Lasting lessons in outdoor learning: A facilitation model emerging from 30 years of reflective practice. Ecopsychology, 10(4), 195-204. https://doi.org/10.1089/eco.2018.0036

Gyimóthy, S. (2010). Thrillscapes: Wilderness mediated as playground. In B. Knudsen \& A. Waade (Eds.), Re-investing authenticity (pp. 254-265). Channel View Publications. https://doi.org/10.21832/9781845411 299-021

Haneishi, K., Fry, A. C., Moore, C. A., Schilling, B. K., Li,Y., \& Fry, M. D. (2007). Cortisol and stress responses during a game and practice in female collegiate soccer players. Fournal of Strength and Conditioning Research, 21(2), 583-588. https://doi.org/10.1519/R-20496.1

Hanin, Y. L. (2000). Emotions in sport. Human Kinetics.

Hanin,Y. L., \& Syrja, P. (1995). Performance affect in junior ice hockey players: An application of the individual zones of optimum functioning model. The Sports Psychologist, 9(2), 169-187. https://doi.org/10.1123/ tsp.9.2.169

Hardy, L., \& Parfitt, G. (1991). A catastrophe model of anxiety and performance. British fournal of Psychology, 82(2), 163-178. https://doi.org/10.1111/j.2044-8295.1991.tb02391.x

Humberstone, B., \& Stan, I. (2011). Outdoor learning: Primary pupils' experiences and teachers' interaction in outdoor learning. Education 3-13, 39(5), 529-540. https://doi.org/10.1080/03004279.2010.487837

Humphreys, M. S., \& Revelle, W. (1984). Personality, motivation and performance: A theory of the relationship between individual differences and information processing. Psychological Review, 91(2), 153-184. https:// doi.org/10.1037/0033-295X.91.2.153

Jones, C. D., Hollenhorst, S. J., Perna, F., \& Selin, S. (2000). Validation of the flow theory in an on-site whitewater kayaking setting. Fournal of Leisure Research, 32(2), 247-261. https://doi.org/10.1080/00222216. 2000.11949916

Jones, J., \& Hardy, L. E. (1990). Stress and performance in sport. John Wiley \& Sons.

Kainzinger, S., Arnberger, A., \& Burns, R. C. (2018). An examination of whitewater boaters' place attachment and specialization in four different river settings. Environmental Management, 62(5), 832-844. https://doi. org/10.1007/s00267-018-1082-x

Kennedy, J., \& Russell, C. (2020). Hegemonic masculinity in outdoor education. Fournal of Adventure Education and Outdoor Learning, 21(2), 162-171. https://doi.org/10.1080/14729679.2020.1755706

Khan, Z. A., \& Zafar, S. (2010). The effects of anxiety on cognitive processing in English language learning. English Language Teaching, 3(2), 199-209. https://doi.org/10.5539/elt.v3n2p199

Kizer, K.W. (1987). Medical aspects of white-water kayaking. The Physician and Sportsmedicine, 15(7), $128-137$. https://doi.org/10.1080/00913847.1987.11702036

Kolb, D. A. (1984). The process of experiential learning. Experiential learning: Experience as the source of learning and development. Prentice-Hall.

Krane, V. (1992). Conceptual and methodological considerations in sport anxiety research: From the inverted-U hypothesis to catastrophe theory. Quest, 44(1), 72-87. https://doi.org/10.1080/00336297.1992.10484042

Lang, P. J. (1985). The cognitive psychophysiology of emotion: Fear and anxiety. In A. H. Tuma \& J. D. Maser (Eds.), Anxiety and the anxiety disorders (pp. 131-170). Erlbaum.

Lazarus, R. S., \& Folkman, S. (1984). Stress, appraisal, and coping. Springer.

Lazarus, R. S., \& Folkman, S. (1986). Cognitive theories of stress and the issue of circularity. In M. H. Appley \& R. Trumbull (Eds.), Dynamics of stress: Physiological, psychological, and social perspectives (pp. 63-80). Plenum Press.

Linnenbrink, E. A., \& Pintrich, P. R. (2003). The role of self-efficacy beliefs in student engagement and learning in the classrooom. Reading and Writing Quarterly, 19(2), 119-137. https://doi.org/10.1080/10573560308223 


\section{"... the thought that I could fip and die today made me feel anxious"}

Little, R. J. A. (1988). A test of missing completely at random for multivariate data with missing values. Fournal of the American Statistical Association, 83(404), 1198-1202. https://doi.org/10.1080/01621459.1988. 10478722

Luszczynska, A., Gutiérrez-Doña, B., \& Schwarzer, R. (2005). General self-efficacy in various domains of human functioning: Evidence from five countries. International fournal of Psychology, 40(2), 80-89. https://doi.org/10.1080/00207590444000041

MacGregor, J. (1866). A thousand miles in the Rob Roy canoe on rivers and lakes of Europe. Simpson Low, Son, and Marston.

Martens, R., Burton, D., Vealey, R., Bump, L., \& Smith, D. (1990). Development and validation of competitive state anxiety inventory-2. In R. Martens, R. Vealey, \& D. Burton (Eds.), Competitive anxiety in sport (pp. 117-178). Human Kinetics.

Masters, R. S. W. (1992). Knowledge, knerves and know-how: The role of explicit verses implicit knowledge in the breakdown of a complex motor skill under pressure. British fournal of Psychology, 83(3), 343-358. https://doi.org/10.1111/j.2044-8295.1992.tb02446.x

McKenzie, M. (2003). Beyond "the outward bound process": Rethinking student learning. Fournal of Experiential Education, 26(1), 8-23. https://doi.org/10.1177/105382590302600104

Moore, S. C., \& Oaksford, M. (2002). Some long-term effects of emotion on cognition. British fournal of Psychology, 93(3), 383-395. https://doi.org/10.1348/000712602760146341

Muntz, M., \& Müller, J. (2016). Mental health benefits of outdoor adventures: Results from two pilot studies. Fournal of Adolescence, 49, 105-114. https://doi.org/10.1016/j.adolescence.2016.03.009

Murdoch, J., \& Kelly, L. K. (2018). Whitewater rafting and kayaking deaths in Colorado: Increasing preventative measures by understanding risk factors. Academic Forensic Pathology, 8(1), 44-49. https://doi. org/10.23907/2018.003

Neill, J. T. (1997, January 20-24). Gender: How does it affect the outdoor education experience [Conference presentation]. 10th National Outdoor Education Conference, Sydney, Australia.

Norwegian Canoe Federation. (2021). White water kayaking instructor education. https://padling.no/vaattkort/ hva-er-vaattkort/de-ulike-kursene-i-npf-vaattkort/elvepadling/veilederkurs-elv/

Orson, C. N., McGovern, G., \& Larson, R. W. (2020). How challenges and peers contribute to socialemotional learning in outdoor adventure education programs. Fournal of Adolescence, 81, 7-18. https://doi. org/10.1016/j.adolescence.2020.02.014

Outdoor Foundation. (2020). 2019 Outdoor participation report. https://outdoorindustry.org/resource/2019outdoor-participation-report/

Perry, R. P., Hall, N. C., \& Ruthig, J. C. (2007). Perceived (academic) control and scholastic attainment in higher education. In R. P. Perry \& J. C. Smart (Eds.), The scholarship of teaching and learning in higher education: An evidence-based perspective (pp. 477-551). Springer.

Pijpers, J. R., Oudejans, R. D., Holscheimer, F., \& Bakker, F. C. (2003). Anxiety-performance relationships in climbing: A process-orientated approach. Psychology of Sport and Exercise, 4(3), 283-304. https://doi. org/10.1016/S1469-0292(02)00010-9

Priest, S., \& Gass, M. A. (2018). Effective leadership in adventure programming (3rd ed.). Human Kinetics.

Puskar, K., Bernardo, L. M., Ren, D., Stark, K. H., \& Lester, S. (2009). Sex differences in self-reported anxiety in rural adolescents. International fournal of Mental Health Nursing, 18(6), 417-423. https://doi. org/10.1111/j.1447-0349.2009.00622.x

Reed, J., \& Smith, H. (2021). "Everything we do will have an element of fear in it": Challenging assumptions of fear for all in outdoor adventurous education. Fournal of Adventure Education and Outdoor Learning, 1-13. https://doi.org/10.1080/14729679.2021.1961092

Rose, J., Paisley, K., Sibthorp, J., Furman, N., \& Gookin, J. (2010). Adventure education learning mechanisms across populations: Qualitative results from the National Outdoor Leadership School. Fournal of Outdoor Recreation, Education and Leadership, 2(2), 68-72. https://doi.org/10.7768/1948-5123.1063

Schuett, M. A. (1993). Refining measures of adventure recreation involvement. Leisure Sciences, 15(3), $205-216$. https://doi.org/10.1080/01490409309513200

Schunk, D. H. (1995). Self-efficacy and education and instruction. In J. E. Maddux (Eds.), Self-efficacy, adaptation, and adjustment: Theory, research, and application (pp. 281-303). Plenum Press.

Usher, E. L., \& Pajares, F. (2008). Sources of self-efficacy in schools: Critical review of the literature and future directions. Review of Educational Research, 78(4), 751-796. https://doi.org/10.3102/0034654308321456

Walsh, V., \& Golins, G. (1976). The exploration of the Outward Bound process. Colorado Outward Bound. 


\section{S. K. Schmidt, M. Barker E F. Byrne}

Warren, K. (2002). Preparing the next generation: Social justice in outdoor leadership education and training. Fournal of Experiential Education, 25(1), 231-238. https://doi.org/10.1177/105382590202500107

Warren, K. (2016). Gender in outdoor studies. In B. Humberstone, H. Prince, \& K. A. Henderson (Eds.), Routledge international handbook of outdoor studies (pp. 360-368). Routledge.

Whiting, J. W., Pawelko, K. A., Green, G. T., \& Larson, L. R. (2011). Whitewater kayaking: A social world investigation. Illuminare, 9, 2-15.

Witman, J. P. (1995). Characteristics of adventure programs valued by adolescents intreatment. Monograph on Youth in the 1990s, 4, 127-135.

Young, A. B. \& Ewert, A. (1992). Fear in outdoor education: The influence of gender and program. Coalition for Education in the Outdoors.

Zaichkowsky, L. D., \& Baltzell, A. (2001). Arousal and performance. In R. N. Singer, H. A. Hausenblas, \& C. M. Janelle (Eds.), Handbook of sport psychology (pp. 319-339). John Wiley.

Zinke, P., Sandvik, D., Nesheim, I., \& Seifert-Dähnn, I. (2018). Comparing three approaches to estimating optimum white water kayak flows in western Norway. Water, 10(12), 1761-1780. https://doi.org/10.3390/ w10121761 


\section{Appendix 1}

CODE

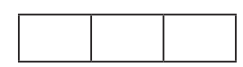

SITE

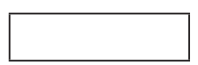

\section{Kayaking Emotion Thermometer (KET)}

Please indicate with a cross where on each line you think best describes how you are currently feeling.

\begin{tabular}{r|l|l} 
Not at all \\
excited
\end{tabular} \mid $\begin{aligned} & \text { Extremely } \\
& \text { excited }\end{aligned}$

\begin{tabular}{r|r|r} 
Not at all \\
anxious
\end{tabular} \mid $\begin{aligned} & \text { Extremely } \\
& \text { anxious }\end{aligned}$

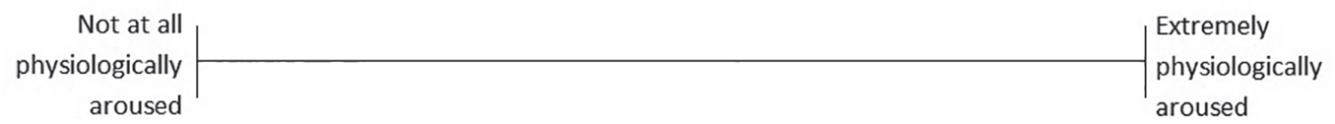

Please state what makes you feel the way you do: 